\title{
Valuable Serum Markers in Pulmonary Alveolar Proteinosis
}

\author{
Shenyun Shi $\mathbb{D}^{1},{ }^{1}$ Lulu Chen $\mathbb{D}^{2},{ }^{2}$ Xiaohua Qiu $\mathbb{D}^{2},{ }^{2}$ Qi Zhao $\mathbb{D}^{\circ},{ }^{2}$ Yonglong Xiao $\mathbb{D}^{2}{ }^{2}$ \\ and Xin Yan iD $^{2}$ \\ ${ }^{1}$ Department of Respiratory Medicine, Nanjing Drum Tower Hospital, Clinical College of Nanjing Medical University, Nanjing, \\ 210008 Jiangsu, China \\ ${ }^{2}$ Department of Respiratory Medicine, Nanjing Drum Tower Hospital, Nanjing University Medical School, Nanjing 210008, China
}

Correspondence should be addressed to Yonglong Xiao; yonglong11a@163.com and Xin Yan; yanxin8612@126.com

Received 15 April 2019; Revised 23 July 2019; Accepted 19 August 2019; Published 11 November 2019

Academic Editor: Roberta Rizzo

Copyright (C) 2019 Shenyun Shi et al. This is an open access article distributed under the Creative Commons Attribution License, which permits unrestricted use, distribution, and reproduction in any medium, provided the original work is properly cited.

Objective. Several serum markers were reported to reflect the severity of pulmonary alveolar proteinosis (PAP). The aim of this study is to investigate a reliable and facile marker to access and monitor the clinical course of PAP in a large cohort. Methods. PAP patients from January 2010 to June 2018 were enrolled. Hospital records were used as data sources. The levels of various serum indicators were detected. We evaluated the correlation between pulmonary function test results and clinical variables. Results. Diffusion capacity for carbon monoxide (DLCO) level was positively correlated with the level of high-density lipoprotein cholesterol $(\mathrm{HDL}-\mathrm{C})(P<0.05)$ in 122 patients of PAP at baseline. The levels of HDL-C and DLCO significantly increased while carcinoembryonic antigen (CEA), CYFRA21-1, neuron-specific enolase (NSE), and lactic dehydrogenase (LDH) levels decreased six months after granulocyte-macrophage colony-stimulating factor (GM-CSF) inhalation therapy between 14 patients with PAP. Nevertheless, the increased DLCO was significantly correlated with decreased CEA $(r=-0.579, P=0.031)$ and CYFRA 21-1 $(r=-0.632, P=0.015)$. In 10 PAP patients without GM-CSF inhalation therapy, HDL-C and DLCO significantly decreased while NSE and LDH levels increased after six months of follow-up. The decreased DLCO was significantly correlated with increased LDH $(r=-0.694, P=0.026)$. Conclusions. Serum CEA, CYFRA21-1, and LDH are valuable serum markers for the evaluation of disease activity of PAP and may predict the response to treatment of PAP.

\section{Background}

Pulmonary alveolar proteinosis (PAP) is a rare and severe disease in which characterized by the accumulation of lipoproteinaceous material within the alveoli and terminal airways [1]. The clinical feature of the disease is progressive exertional dyspnea of insidious onset and cough, also with a high risk of pulmonary infections causing respiratory insufficiency. PAP has been described in three forms clinically: primary PAP that can be autoimmune PAP which is associated with elevated levels of autoantibodies against granulocyte-macrophage colony-stimulating factor (GM-CSF) or hereditary PAP which is due to gene mutations of GM-CSF receptor alpha and beta genes (CSF2RA and CSF2RB, respectively), secondary PAP, and congenital PAP. More than $90 \%$ pulmonary alveolar proteinosis is autoimmune [2].
It has been reported that in patients with primary PAP, some pulmonary cytokine level could be used to assess and monitor disease progression. For example, the level of tumor markers, which is elevated both in the serum and bronchoalveolar lavage fluid (BALF) of humans with acquired pulmonary alveolar proteinosis [3]. Similarly, the level of serum lipids is also elevated in the serum of humans with the acquired disease [4]. However, these results have not yet been performed in larger PAP population samples. It is unknown whether these markers are changed with the course of PAP. This study is intended to find a reliable and facile marker to access and manage the disease activity of PAP.

\section{Subjects and Methods}

2.1. Subjects. This study included 122 PAP patients who were recruited from the inpatient of the Department of Respira- 
tion of Nanjing Drum Tower Hospital between January 2010 and June 2018 and diagnosed by transbronchial lung biopsy. All subjects gave informed written consent to participate. Patients were excluded from the study if they had sarcoidosis, occupational lung disease, idiopathic pulmonary fibrosis, pulmonary tuberculosis, COPD, and cancer. According to the disease severity score (DSS) of PAP defined by Inoue et al. [5], the grades were as follows: grade $1, \mathrm{PaO} 2 \geq 70 \mathrm{mmHg}$ without respiratory symptoms; grade $2, \mathrm{PaO} 2 \geq 70 \mathrm{mmHg}$ with respiratory symptoms; grade 3, $70 \mathrm{mmHg}>\mathrm{PaO} 2 \geq 60 \mathrm{mmHg}$; grade 4, $60 \mathrm{mmHg}>$ $\mathrm{PaO} 2 \geq 50 \mathrm{mmHg}$; and grade $5, \mathrm{PaO} 2<50 \mathrm{mmHg}$. Arterial blood gas of PAP patients was analyzed when they were breathing room air. Among 122 PAP patients in this study, the disease severity score of 9 PAP patients at the baseline was classified into grade 1 . The DSS score of 52 PAP patients was classified into grade 2 . There were 30 PAP patients whose DSS score were classified into grade 3 . There were 20 and 11 PAP patients who were, respectively, classified into grade 4 and grade 5 .

\subsection{Method}

2.2.1. Laboratory Tests. Routine biochemical analyses including plasma lipids and serum lactate dehydrogenase (LDH) were measured with commercial kits using an automated chemistry analyzer (Chemistry Analyzer Au2700, Olympus Medical Engineering Company, Japan). The white blood cell count (WBCC), neutrophil, lymphocyte, and monocyte differentials were determined using an automated blood cell counter (Beckman Coulter Ireland Inc. Mervue, Galway, Ireland). CEA, CYFRA 21-1, and neuron-specific enolase (NSE) were measured with an enzyme immunoradiometric assay kit (TFB, Tokyo, Japan). IgA, IgG, IgM, IgE, C3, and $\mathrm{C} 4$ were determined using immunoturbidimetry. Pulmonary function tests (Fukuda Sangyo, Japan) were performed in PAP patients.

2.2.2. GM-CSF Inhalation. In our hospital, there are only a small number of patients treated with whole lung lavage (WLL). However, the follow-up data of the patients treated with WLL is not available. So far, there have been no patients treated with rituximab. In this study, fourteen patients were treated with GM-CSF inhalation. These patients elected to initiate inhaled GM-CSF (200 mg) twice daily, three times per week, administered two weeks per month for six months.

2.2.3. Statistical Analysis. Data are expressed as mean \pm SD. Correlations between DLCO-SB and other parameters were evaluated by Pearson's correlation analysis. The differences of DLCO-SB and other parameters before and after GM-CSF inhalation or between baseline and six-month follow-up without GM-CSF inhalation were determined by the paired $t$-test. The relationship between variations of DLCO-SB and variations of other parameters were also assessed by Pearson's correlation analysis. Data were analyzed using SPSS18.0 statistical software, with significance defined as $P<0.05$ (two-sided).
TABle 1: The clinical and biochemical properties of 122 PAP patients.

\begin{tabular}{|c|c|}
\hline & $\mathrm{PAP}(n=122)$ \\
\hline Age (years) & $46.61 \pm 11.08$ \\
\hline Male/female & $77 / 45$ \\
\hline Smoking (yes/no) & $72 / 50$ \\
\hline $\mathrm{SBP}(\mathrm{mmHg})$ & $126.28 \pm 10.94$ \\
\hline $\mathrm{DBP}(\mathrm{mmHg})$ & $76.69 \pm 7.72$ \\
\hline HDL-C $(\mathrm{mmol} / \mathrm{l})$ & $1.07 \pm 0.39$ \\
\hline LDL-C (mmol/l) & $2.78 \pm 0.79$ \\
\hline $\mathrm{TC}(\mathrm{mmol} / \mathrm{l})$ & $4.83 \pm 0.92$ \\
\hline $\mathrm{TG}(\mathrm{mmol} / \mathrm{l})$ & $1.65 \pm 0.94$ \\
\hline apoA1 (g/l) & $1.97 \pm 0.79$ \\
\hline $\operatorname{apoB}(g / l)$ & $0.93 \pm 0.25$ \\
\hline $\operatorname{Ig} A$ & $1.97 \pm 0.79$ \\
\hline IgG & $11.46 \pm 2.58$ \\
\hline $\operatorname{Ig} M$ & $1.51 \pm 0.72$ \\
\hline $\operatorname{IgE}$ & $94.94 \pm 11.54$ \\
\hline $\mathrm{C} 3$ & $1.05 \pm 0.26$ \\
\hline $\mathrm{C} 4$ & $0.24 \pm 0.08$ \\
\hline $\operatorname{WBCC}\left(10^{9} / 1\right)$ & $6.45 \pm 1.56$ \\
\hline Neutrophil count $\left(10^{9} / 1\right)$ & $3.88 \pm 1.14$ \\
\hline Lymphocyte count $\left(10^{9} / 1\right)$ & $1.89 \pm 0.60$ \\
\hline Monocyte count $\left(10^{9} / 1\right)$ & $0.47 \pm 0.12$ \\
\hline CEA (ng/ml) & $4.68 \pm 0.147$ \\
\hline CYFRA21-1 (ng/ml) & $10.18 \pm 2.23$ \\
\hline NSE (ng/ml) & $20.16 \pm 5.69$ \\
\hline $\mathrm{LDH}(\mathrm{IU} / \mathrm{l})$ & $284.52 \pm 21.95$ \\
\hline DLCO-SB (\%) & $63.72 \pm 15.82$ \\
\hline
\end{tabular}

Abbreviations: SBP: systolic blood pressure; DBP: diastolic blood pressure; TC: total cholesterol; TG: triacylglyceride; LDL-C: high-density lipoprotein cholesterol; HDL-C: high-density lipoprotein cholesterol; WBCC: while blood cell count; CEA: carcinoembryonic antigen; NSE: neuron-specific enolase; LDH: lactic dehydrogenase; DLCO: diffusion capacity for carbon monoxide.

\section{Results}

3.1. Baseline Characteristics of PAP Patients. Clinical and biochemical characteristics of the PAP patients are listed in Table 1. The mean age at diagnosis was $46.61 \pm 11.08$ years. Predominantly male patients had PAP (63.11\%). Most patients (59.02\%) were smokers before diagnosis. Mean serum CEA, CYFRA21-1, and NSE levels were $4.68 \pm 0.147 \mathrm{ng} / \mathrm{ml}$, $10.18 \pm 2.23 \mathrm{ng} / \mathrm{ml}$, and $201.16 \pm 5.69 \mathrm{ng} / \mathrm{ml}$, respectively. Mean DLCO-SB was $63.72 \pm 15.82 \%$.

3.2. The Relationships between DLCO-SB with Other Parameters in Patients of PAP at Baseline. Table 2 showed that DLCO-SB was negatively correlated with TC, LDL-C, WBCC, neutrophil count, CEA, CYFRA21-1, NSE, and LDH while positively correlated with HDL-C $(P<0.05)$ in 
TABLE 2: Pearson's correlation analysis of DLCO-SB with other parameters in patients of PAP at baseline.

\begin{tabular}{lcc}
\hline & $r$ & $P$ \\
\hline Age (years) & 0.116 & 0.203 \\
SBP $(\mathrm{mmHg})$ & 0.073 & 0.312 \\
DBP $(\mathrm{mmHg})$ & 0.086 & 0.254 \\
HDL-C $(\mathrm{mmol} / \mathrm{l})$ & 0.467 & $<0.001$ \\
LDL-C $(\mathrm{mmol} / \mathrm{l})$ & -0.363 & $<0.001$ \\
TC $(\mathrm{mmol} / \mathrm{l})$ & -0.364 & $<0.001$ \\
TG $(\mathrm{mmol} / \mathrm{l})$ & 0.137 & 0.135 \\
apoA1 $(\mathrm{g} / \mathrm{l})$ & 0.175 & 0.056 \\
apoB $(\mathrm{g} / \mathrm{l})$ & 0.091 & 0.320 \\
IgA & -0.112 & 0.221 \\
IgG & -0.176 & 0.053 \\
IgM & -0.151 & 0.098 \\
IgE & 0.041 & 0.658 \\
C3 & -0.011 & 0.905 \\
C4 & -0.090 & 0.325 \\
WBCC $\left(10^{9} / \mathrm{l}\right)$ & -0.278 & 0.002 \\
Neutrophil count $\left(10^{9} / \mathrm{l}\right)$ & -0.336 & $<0.001$ \\
Lymphocyte count $\left(10^{9} / \mathrm{l}\right)$ & 0.075 & 0.416 \\
Monocyte count $\left(10^{9} / \mathrm{l}\right)$ & 0.048 & 0.591 \\
CEA & -0.440 & $<0.001$ \\
CYFRA21-1 & -0.468 & $<0.001$ \\
NSE & -0.416 & $<0.001$ \\
LDH & -0.472 & $<0.001$ \\
\hline
\end{tabular}

patients of PAP at baseline. Nevertheless, we did not observe the statistically significant relationship between DLCO-SB and age, SBP, DBP, TG, apoA1, apoB, IgA, IgG, IgM, IgE, C3, C4, lymphocyte count, and monocyte count.

3.3. Changes in Serum DLCO-SB and Other Parameters Six Months after GM-CSF Inhalation Therapy in PAP Patients. Inhaled GM-CSF was administered to 14 patients. HDL-C and DLCO-SB significantly increased while CEA, CYFRA21-1, NSE, and LDH levels significantly decreased six months after GM-CSF inhalation therapy. There were no differences of TC, TG, LDL-C, apoA1, apoB, WBCC, neutrophil count, lymphocyte count, and monocyte count before and after treatment (Table 3).

3.4. The Relationship between Variations of DLCO-SB and Variations of Other Parameters after GM-CSF Inhalation Therapy in PAP Patients. The increased DLCO-SB was significantly correlated with decreased CEA $(r=-0.579$, $P=0.031)$ and CYFRA 21-1 $(r=-0.632, P=0.015)$ but not with variations of HDL-C, NSE, and LDH (Table 4, Figures 1 and 2).

3.5. Comparison of DLCO-SB and Other Parameters between Baseline and Six-Month Follow-Up in PAP Patients without GM-CSF Inhalation Therapy. 10 PAP patients without GM-CSF inhalation therapy were enrolled in our study. After six months of follow-up, HDL-C and DLCO-SB
TABLE 3: Comparison of DLCO-SB and other parameters before and after inhalation of the GM-CSF treatment in PAP patients.

\begin{tabular}{lcc}
\hline & $\begin{array}{c}\text { Before GM-CSF } \\
\text { treatment }(n=14)\end{array}$ & $\begin{array}{c}\text { After GM-CSF } \\
\text { treatment }(n=14)\end{array}$ \\
\hline HDL-C $(\mathrm{mmol} / \mathrm{l})$ & $0.86 \pm 0.23$ & $1.13 \pm 0.32^{\mathrm{a}}$ \\
LDL-C $(\mathrm{mmol} / \mathrm{l})$ & $2.69 \pm 0.64$ & $2.57 \pm 0.83$ \\
TC $(\mathrm{mmol} / \mathrm{l})$ & $4.47 \pm 0.80$ & $4.38 \pm 0.81$ \\
TG $(\mathrm{mmol} / \mathrm{l})$ & $1.58 \pm 0.68$ & $1.73 \pm 0.93$ \\
apoA1 $(\mathrm{g} / \mathrm{l})$ & $1.03 \pm 0.29$ & $1.08 \pm 0.30$ \\
apoB $(\mathrm{g} / \mathrm{l})$ & $0.93 \pm 0.21$ & $0.89 \pm 0.25$ \\
WBCC $\left(10^{9} / \mathrm{l}\right)$ & $5.12 \pm 1.41$ & $5.63 \pm 1.91$ \\
Neutrophil count $\left(10^{9} / \mathrm{l}\right)$ & $2.79 \pm 1.14$ & $3.17 \pm 1.21$ \\
Lymphocyte count $\left(10^{9} / \mathrm{l}\right)$ & $1.78 \pm 0.30$ & $1.95 \pm 0.58$ \\
Monocyte count $\left(10^{9} / \mathrm{l}\right)$ & $0.38 \pm 0.16$ & $0.39 \pm 0.11$ \\
CEA & $4.28 \pm 1.28$ & $2.18 \pm 1.16^{\mathrm{a}}$ \\
CYFRA21-1 & $10.97 \pm 2.95$ & $6.92 \pm 1.55^{\mathrm{a}}$ \\
NSE & $21.71 \pm 5.01$ & $17.66 \pm 3.83^{\mathrm{a}}$ \\
LDH & $300.64 \pm 15.81$ & $235.00 \pm 10.78^{\mathrm{a}}$ \\
DLCO-SB & $58.06 \pm 10.36$ & $71.01 \pm 12.92^{\mathrm{a}}$ \\
\hline Compan
\end{tabular}

Compared with before GM-CSF treatment, ${ }^{\mathrm{a}} \mathrm{P}<0.05$.

TABLE 4: The relationship between variations of DLCO-SB and variations of other parameters after inhalation of the GM-CSF treatment in PAP patients.

\begin{tabular}{lcc}
\hline & $r$ & $P$ \\
\hline Variations of HDL-C (\%) & -0.283 & 0.327 \\
Variations of CEA (\%) & -0.579 & 0.031 \\
Variations of CYFRA21-1 (\%) & -0.632 & 0.015 \\
Variations of NSE (\%) & -0.429 & 0.126 \\
Variations of LDH (\%) & -0.344 & 0.228 \\
\hline
\end{tabular}

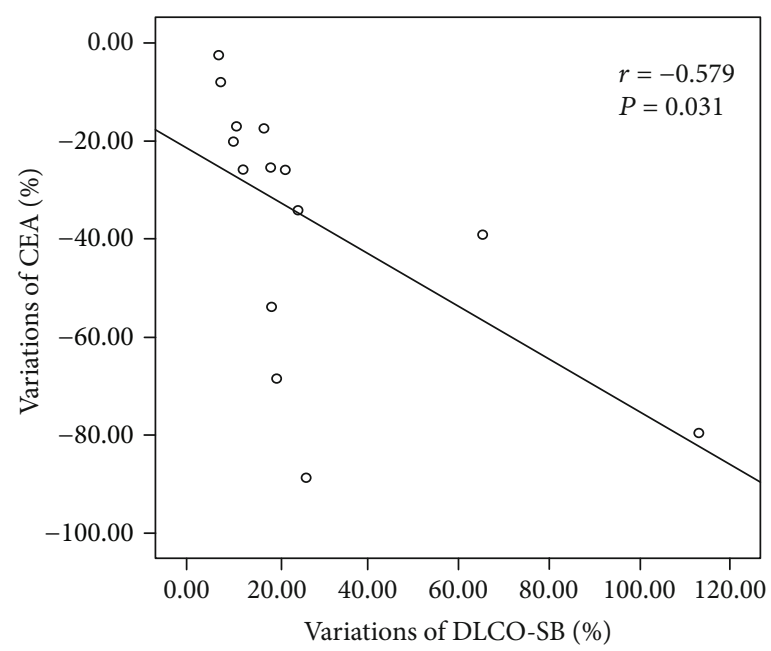

FIgURE 1: The relationship between variations of DLCO-SB and variations of CEA after inhalation of the GM-CSF treatment in PAP patients. 


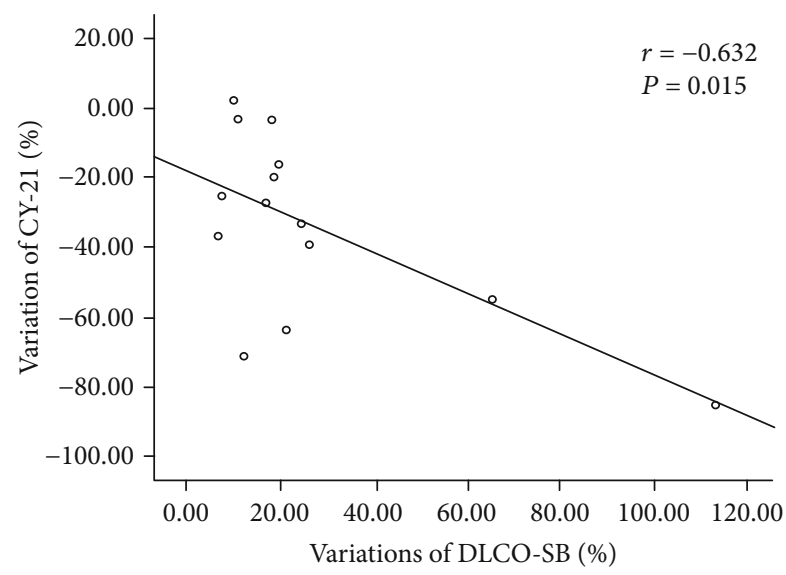

FIGURE 2: The relationship between variations of DLCO-SB and variations of CYFRA21-1 after inhalation of the GM-CSF treatment in PAP patients.

TABLE 5: Comparison of DLCO-SB and other parameters between baseline and six-month follow-up in PAP patients without inhalation of the GM-CSF treatment.

\begin{tabular}{lcc}
\hline & $\begin{array}{c}\text { Baseline } \\
(n=10)\end{array}$ & $\begin{array}{c}\text { Six-month follow-up } \\
(n=10)\end{array}$ \\
\hline HDL-C $(\mathrm{mmol} / \mathrm{l})$ & $1.33 \pm 0.30$ & $1.05 \pm 0.31^{\mathrm{a}}$ \\
LDL-C $(\mathrm{mmol} / \mathrm{l})$ & $2.52 \pm 0.56$ & $2.89 \pm 0.77$ \\
TC $(\mathrm{mmol} / \mathrm{l})$ & $4.49 \pm 0.95$ & $4.91 \pm 1.07$ \\
TG $(\mathrm{mmol} / \mathrm{l})$ & $1.76 \pm 0.90$ & $1.25 \pm 0.75$ \\
apoA1 $(\mathrm{g} / \mathrm{l})$ & $1.18 \pm 0.35$ & $1.21 \pm 0.22$ \\
apoB $(\mathrm{g} / \mathrm{l})$ & $0.88 \pm 0.21$ & $0.99 \pm 0.28$ \\
WBCC $\left(10^{9} / \mathrm{l}\right)$ & $5.47 \pm 1.59$ & $5.19 \pm 1.31$ \\
Neutrophil count $\left(10^{9} / \mathrm{l}\right)$ & $3.11 \pm 1.37$ & $2.88 \pm 1.05$ \\
Lymphocyte count $\left(10^{9} / \mathrm{l}\right)$ & $1.68 \pm 0.41$ & $1.79 \pm 0.39$ \\
Monocyte count $\left(10^{9} / \mathrm{l}\right)$ & $0.31 \pm 0.11$ & $0.32 \pm 0.08$ \\
CEA & $2.12 \pm 1.85$ & $2.95 \pm 1.54$ \\
CYFRA21-1 & $5.42 \pm 2.02$ & $7.25 \pm 2.42$ \\
NSE & $15.43 \pm 4.41$ & $17.79 \pm 5.17^{\mathrm{a}}$ \\
LDH & $205.50 \pm 23.97$ & $257.30 \pm 26.48^{\mathrm{a}}$ \\
DLCO-SB & $78.06 \pm 15.00$ & $66.81 \pm 17.80^{\mathrm{a}}$ \\
\hline Compred & &
\end{tabular}

Compared with baseline, ${ }^{\mathrm{a}} P<0.05$.

significantly decreased while NSE and LDH levels significantly increased in $10 \mathrm{PAP}$ patients without GM-CSF inhalation therapy. There were no differences of TC, TG, LDL-C, apoA1, apoB, WBCC, neutrophil count, lymphocyte count, monocyte count, CEA, and CYFRA21-1 between baseline and 6-month follow-up (Table 5).

3.6. The Relationship between Variations of DLCO-SB and Variations of Other Parameters in PAP Patients without GM-CSF Inhalation Therapy after Six Months of Follow-Up. The decreased DLCO-SB was significantly correlated with increased LDH $(r=-0.694, P=0.026)$ but not with variations of HDL-C, CEA, CYFRA21-1, and NSE (Table 6, Figure 3).
TABLE 6: The relationship between variations of DLCO-SB and variations of other parameters in PAP patients without inhalation of the GM-CSF treatment after six months of follow-up.

\begin{tabular}{lcc}
\hline & $r$ & $P$ \\
\hline Variations of HDL-C (\%) & -0.189 & 0.601 \\
Variations of CEA (\%) & -0.483 & 0.158 \\
Variations of CY-21 (\%) & -0.446 & 0.196 \\
Variations of NSE (\%) & -0.545 & 0.104 \\
Variations of LDH (\%) & -0.694 & 0.026 \\
\hline
\end{tabular}

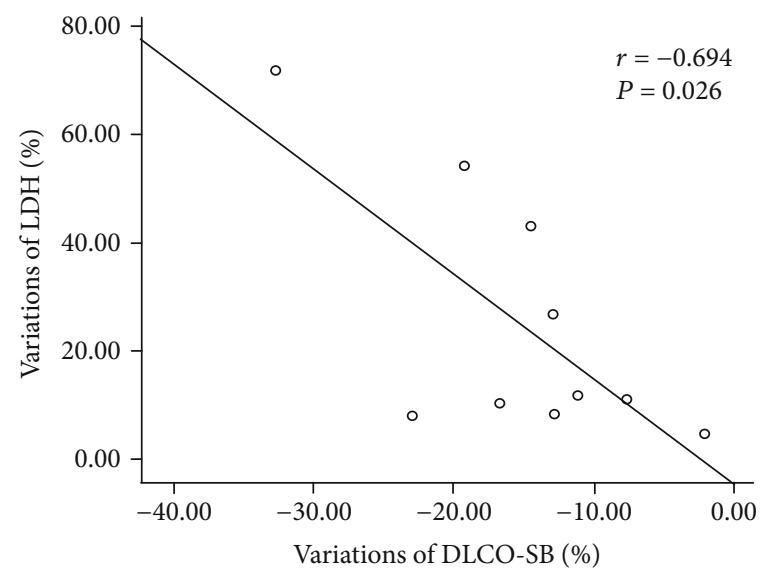

FIgURE 3: The relationship between variations of DLCO-SB and variations of $\mathrm{LDH}$ in PAP patients without inhalation of the GM-CSF treatment after six months of follow-up.

\section{Discussion}

Compared with other similar studies, this retrospective study evaluated valuable serum makers in larger PAP samples. In this study, we measured the levels of various clinical variables in the serum of 122 patients with PAP. Levels of LDH, CEA, NSE, neutrophil count, TC, HDL-C, and LDL-C were significantly distinguished in PAP patients compared with normal subjects. By Pearson's correlation analysis, there was a significant correlation between the level of LDH, CEA, NSE, CYF21-1, TC, HDL-C, and LDL-C in serum and pulmonary dysfunction in PAP patients. In addition, we found that there was a significant inverse correlation between the level of CEA and CYF21-1 and pulmonary function in 14 PAP patients who had been administered inhaled GM-CSF therapy for six months. In 10 PAP patients without GM-CSF therapy, this study showed that an elevation of $\mathrm{LDH}$ was observed and a decrease in DLCO after six months of follow-up.

Elevation of serum markers in PAP patients is associated with impaired metabolism through the dysfunction of alveolar macrophages $[6,7]$. Although tumor markers were widely used in detecting malignancies, they were also detected in nonmalignant diseases. In recent years, there were researches studying tumor markers such as CEA, CYF21-1, and NSE that might reflect the severity of PAP [8-10]. This study showed that LDH, CEA, and CYFRA 21-1 could be sensitive and useful serum markers for the evaluation of disease 
activity of PAP. An elevation of LDH can be found in a variety of systemic inflammatory diseases. Early studies showed that the serum level of $\mathrm{LDH}$ is often slightly elevated and maybe a marker of the severity of PAP [11]. CEA is a cell surface glycoprotein, whose concentration is high in foetal tissues and a variety of tumors, most commonly those of endodermal origin [12]. In fact, CEA localization has been reported in the lungs of PAP patients [13]. A previous study has reported that in nonmalignant pulmonary diseases, elevation of serum CYFRA $21-1$ is due to epithelial damage and its increased production in the epithelium [9].

PAP is a rare disease characterized by the alveolar accumulation of surfactant components, which impairs gas exchange, resulting in respiratory failure. The clinical course is unpredictable. Spontaneous improvement or even cure can occur, and the 5-year actuarial survival is 95\% [14]. The most frequent complications are infectious etiology. Whole lung lavage (WLL) has been the first-line therapy since the $1960 \mathrm{~s}$ [15]. However, WLL is not standardized and international consensus documents are lacking. Moreover, WLL is associated with adverse effects such as infections, fever, convulsions, pneumothorax, pleural effusion, hypoxemia, or even death. $10 \%$ of patients with PAP need repeated whole lung lavage [16]. In recent years, new treatments are available such as subcutaneous or inhaled GM-CSF supplementation, plasmapheresis, or rituximab infusions [17]. Inhaled GM-CSF therapy is currently widely used, but the therapy has a slow onset and has limited efficacy in patients with severe pulmonary function decline in the advanced stage. One retrospective study by Soyez et al., which included 13 PAP patients, reported rituximab could not be as a second-line therapy for patients with PAP [18]. Nowadays, oral statin therapy can be a novel pharmacotherapy of PAP. In a study by McCarthy et al., the expression of cholesterol in alveolar is higher in PAP patients. Statin therapy reduces cholesterol accumulation and ameliorates PAP [19]. However, oral statin therapy has not yet been administered in larger PAP population samples. The present study revealed that there was a significant inverse correlation between the level of LDH, CEA, CYF21-1, and DLCO. In the future, we could monitor the disease activity and effectiveness of various therapies for PAP by detecting the level of LDH, CEA, and CYF21-1.

There are some limitations to this study. First of all, the study is a retrospective observational study. Secondly, the mechanisms responsible for PAP have not been investigated in this study. Finally, it remains unresolved from our investigation, which is the best serum marker of PAP.

\section{Conclusion}

Above all, serum LDH, CEA, and CYF21-1 are valuable and sensitive serum makers for the evaluation of disease activity of PAP and may reflect the response to various treatment of PAP.

\section{Data Availability}

Data can be submitted by corresponding authors in case of a request.

\section{Conflicts of Interest}

The authors declare that there is neither conflict of interest nor financial gain regarding the publication of this paper.

\section{Authors' Contributions}

S-Y S, Y-L X, and X Y were involved in the conception and design. S-Y S, Y-L X, X-H Q, L-L C, and Q Z were involved in the analysis and interpretation. S-Y S, X-H Q, Q Z, and $X$ Y were involved in the acquisition of data. S-Y S, Y-L X, and $\mathrm{X} Y$ were involved in the writing and revisions.

\section{References}

[1] T. Suzuki and B. C. Trapnell, "Pulmonary alveolar proteinosis syndrome," Clinics in Chest Medicine, vol. 37, no. 3, pp. 431440, 2016.

[2] B. C. Trapnell, K. Nakata, F. Bonella et al., "Pulmonary alveolar proteinosis," Nature Reviews Disease Primers, vol. 5, no. 1, article 16, 2019.

[3] Y. Hirakata, J. Kobayashi, Y. Sugama, and S. Kitamura, "Elevation of tumour markers in serum and bronchoalveolar lavage fluid in pulmonary alveolar proteinosis," The European Respiratory Journal, vol. 8, no. 5, pp. 689-696, 1995.

[4] S. H. Rosen, B. Castleman, and A. A. Liebow, "Pulmonary alveolar proteinosis," The New England Journal of Medicine, vol. 258, no. 23, pp. 1123-1142, 1958.

[5] Y. Inoue, B. C. Trapnell, R. Tazawa et al., "Characteristics of a large cohort of patients with autoimmune pulmonary alveolar proteinosis in Japan," American Journal of Respiratory and Critical Care Medicine, vol. 177, pp. 752-762, 2008.

[6] I. R. Doyle, T. E. Nicholas, and A. D. Bersten, "Partitioning lung and plasma proteins: circulating surfactant proteins as biomarkers of alveolocapillary permeability," Clinical and Experimental Pharmacology \& Physiology, vol. 26, no. 3, pp. 185-197, 1999.

[7] C. Hermans and A. Bernard, "Lung epithelium-specific proteins: characteristics and potential applications as markers," American Journal of Respiratory and Critical Care Medicine, vol. 159, no. 2, pp. 646-678, 1999.

[8] S. C. Fang, K. H. Lu, C. Y. Wang, H. T. Zhang, and Y. M. Zhang, "Elevated tumor markers in patients with pulmonary alveolar proteinosis," Clinical Chemistry and Laboratory Medicine, vol. 51, no. 7, pp. 1493-1498, 2013.

[9] T. Arai, Y. Inoue, C. Sugimoto et al., "CYFRA 21-1 as a disease severity marker for autoimmune pulmonary alveolar proteinosis,” Respirology, vol. 19, no. 2, pp. 246-252, 2014.

[10] I. Campo, F. Mariani, G. Rodi et al., "Assessment and management of pulmonary alveolar proteinosis in a reference center," Orphanet Journal of Rare Diseases, vol. 8, no. 1, article 17501172-8-40, p. 40, 2013.

[11] B. C. Trapnell, J. A. Whitsett, and K. Nakata, "Pulmonary alveolar proteinosis," The New England Journal of Medicine, vol. 349, no. 26, pp. 2527-2539, 2003.

[12] H. J. Hansen, J. J. Snyder, E. Miller et al., "Carcinoembryonic antigen (CEA) assay: A laboratory adjunct in the diagnosis and management of cancer," Human Pathology, vol. 5, no. 2, pp. 139-147, 1974.

[13] C. Hamamatsu, T. Fujishima, T. Saito et al., "Two cases of pulmonary alveolar proteinosis with increase of serum 
CEA," Nihon Kyōbu Shikkan Gakkai zasshi, vol. 28, no. 12, pp. 1616-1621, 1990.

[14] S. Jouneau, M. Kerjouan, E. Briens et al., "Pulmonary alveolar proteinosis," Revue des Maladies Respiratoires, vol. 31, no. 10, pp. 975-991, 2014.

[15] M. Beccaria, M. Luisetti, G. Rodi et al., "Long-term durable benefit after whole lung lavage in pulmonary alveolar proteinosis," The European Respiratory Journal, vol. 23, no. 4, pp. 526-531, 2004.

[16] I. Campo, M. Luisetti, M. Griese et al., "Whole lung lavage therapy for pulmonary alveolar proteinosis: a global survey of current practices and procedures," Orphanet Journal of Rare Diseases, vol. 11, no. 1, article 115, 2016.

[17] M. J. McDonnell, C. Reynolds, V. Tormey, J. J. Gilmartin, and R. M. Rutherford, "Pulmonary alveolar proteinosis: report of two cases in the West of Ireland with review of current literature," Irish Journal of Medical Science, vol. 183, no. 1, pp. 123-127, 2014.

[18] B. Soyez, R. Borie, C. Menard et al., "Rituximab for autoimmune alveolar proteinosis, a real life cohort study," Respiratory Research, vol. 19, no. 1, p. 74, 2018.

[19] C. McCarthy, E. Lee, J. P. Bridges et al., "Statin as a novel pharmacotherapy of pulmonary alveolar proteinosis," Nature Communications, vol. 9, no. 1, article 3127, 2018. 


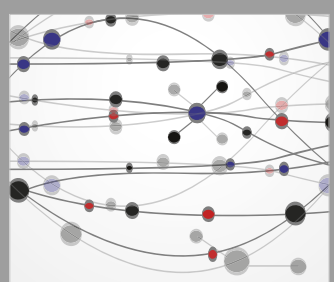

The Scientific World Journal
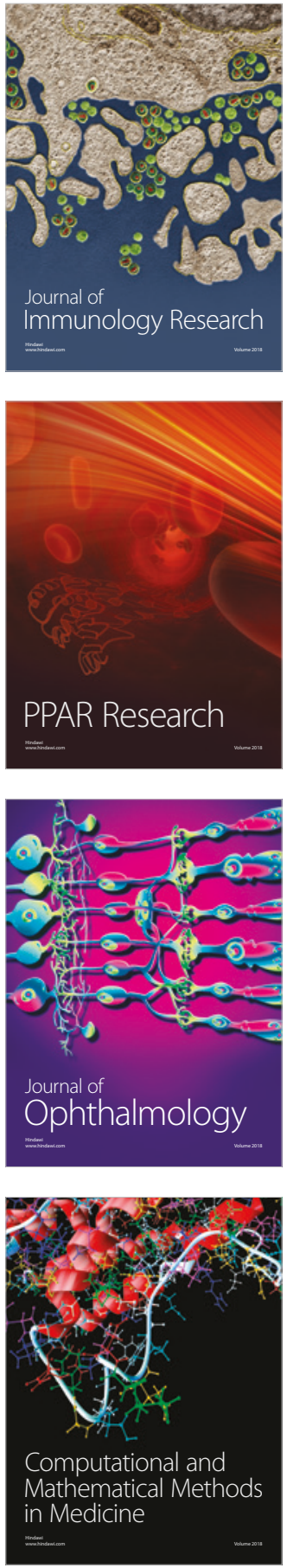

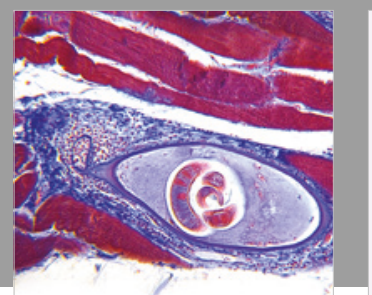

Gastroenterology Research and Practice

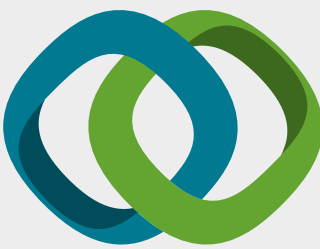

\section{Hindawi}

Submit your manuscripts at

www.hindawi.com
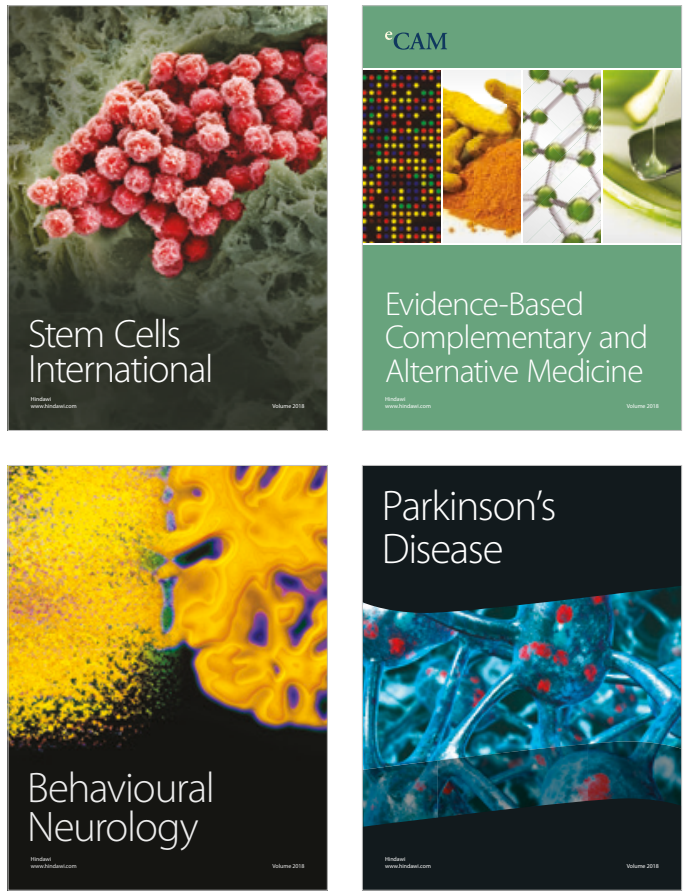

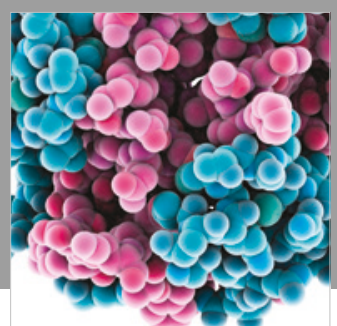

ournal of

Diabetes Research

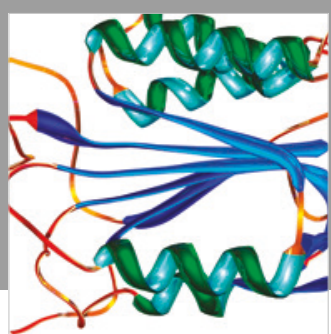

Disease Markers
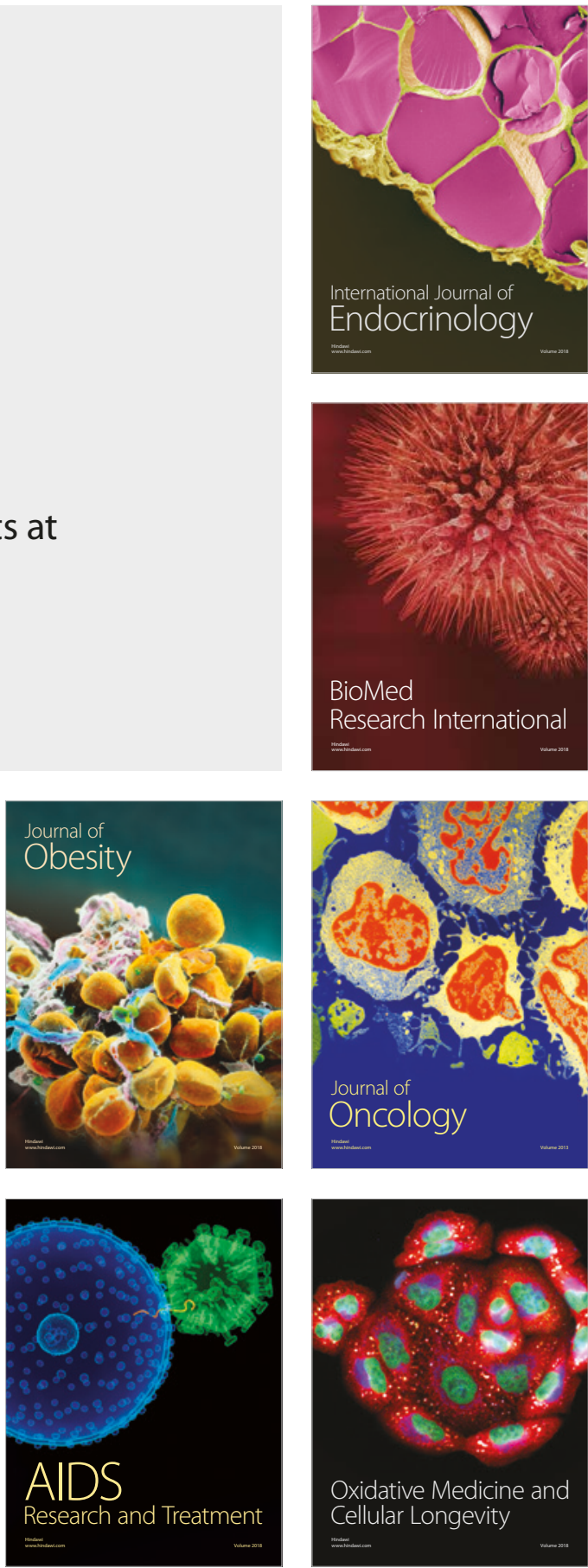